\title{
The complement system in glioblastoma multiforme
}

\author{
T. A. M. Bouwens van der Vlis ${ }^{1,2,3}$, J. M. Kros ${ }^{3}$, D. A. M. Mustafa ${ }^{3}$, R. T. A. van Wijck ${ }^{4}$, L. Ackermans ${ }^{2}$, \\ P. M. van Hagen ${ }^{4,5}$ and P. J. van der Spek,
}

\begin{abstract}
The human complement system is represents the main effector arm of innate immunity and its ambivalent function in cancer has been subject of ongoing dispute. Glioma stem-like cells (GSC) residing in specific niches within glioblastomas (GBM) are capable of self-renewal and tumor proliferation. Recent data are indicative of the influence of the complement system on the maintenance of these cells. It appears that the role of the complement system in glial tumorigenesis, particularly its influence on GSC niches and GSC maintenance, is significant and warrants further exploration for therapeutic interventions.
\end{abstract}

\section{Introduction}

Traditionally, the human complement system is regarded to be a main effector arm of the innate immunity and comprises around thirty soluble and membrane-associated proteins. Innate immunity forms the first line of defense against invading micro-organisms, and is ancient compared to the adaptive immune system. Analogues of components of the mammalian alternative complement pathway have been identified in deuterostomes/protostomes over 1000 million years ago, whereas the first molecules from the jawed-invertebrate specific adaptive immune system emerged at least 400 million years later [63]. After breaching the host's environmental barriers, invading microbes are detected by the pattern recognition molecules (PRM) of the classical (C1q) and lectin (MBL, ficolins) complement pathways (CP, LP) [75, 96]. (Fig. 1). Further, activation of the complement cascade through the AP is achieved through insufficient inhibition of spontaneous hydrolysis of C3 (C3-H20) by the microbe (AP). All three activation pathways converge at the level of $\mathrm{C} 3$ which, after formation of the C3 and C5 convertase complexes, continues with the formation of the terminal complement complex (TCC) either as the pore-like membrane attack complex (MAC) or as cell-activating sC5b-9 [51]. MAC assembly in the cell membrane causes prompt colloid osmotic lysis $[56,59]$.

\footnotetext{
* Correspondence: j.m.kros@erasmusmc.nl

${ }^{3}$ Department of Pathology, Erasmus University Medical Center, Wytemaweg 80, 3015, GE, Rotterdam, The Netherlands

Full list of author information is available at the end of the article
}

Over a century after the initial discovery of the complement system by Buchner et al. it was realized that the actions of complement are not constrained to an effector mechanism of the innate immunity, but are also involved in directing the adaptive immune response, angiogenesis, tissue regeneration, fat metabolism and development of the central nervous system (CNS) [75]. The complement system acts as intricate immune surveillance system that is able to discriminate between healthy host tissue, cellular debris, apoptotic cells and foreign intruders (Fig. 1) and contributes to a large variety of inflammatory-, immune-, ischemic-, age-related pathologic processes of the CNS [75]. A wide repertoire of specific complement inhibitors has been developed against a variety of diseases of which eculizumab, an antibody against $\mathrm{C} 5$ and $\mathrm{C} 1$ (C1-INH) became FDA approved for the treatment of paroxysmal nocturnal hemoglobinuria, atypical hemolytic uremic syndrome and hereditary angiogoedema [1]. In recent years it became clear that many factors of the complement system are expressed in the brain $[60,93]$. The production of the complement proteins in CNS is constrained to microglia, oligodendrocytes, astrocytes and, to a lesser extent, ependymal cells [93]. The complement system appears to be a key player in CNS homeostasis as complement effector mechanisms have been identified in neurogenesis and regulating synaptic pruning [54]. Various pathological conditions cause an imbalance between complement activation and inhibition. 


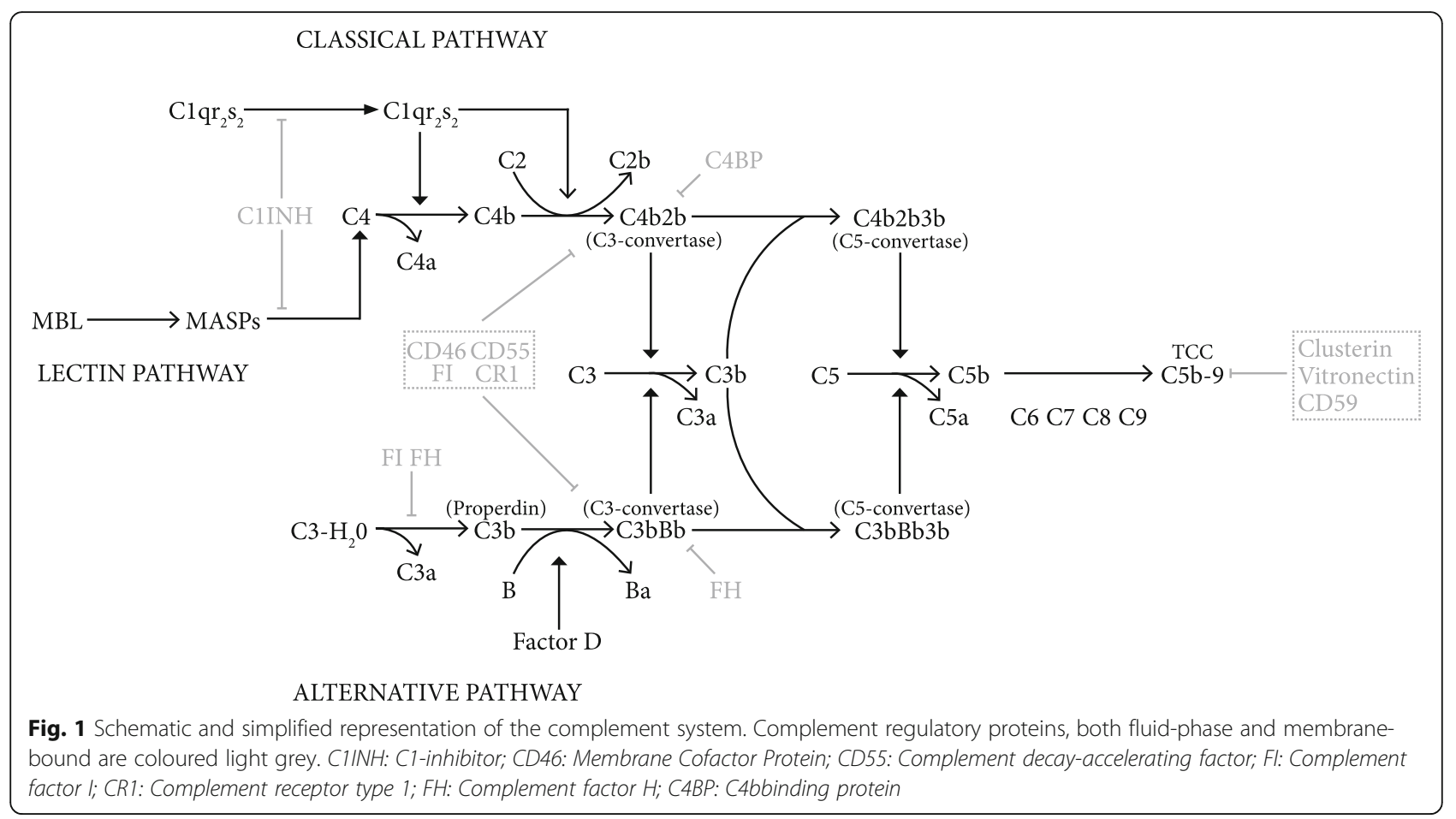

Activation of the complement system contributes to a wide variety of CNS diseases including Alzheimer disease, CNS inflammation, traumatic brain injury and tumors $[6$, 55]. The cross-link between inflammation and cancer is generally accepted as chronic and insidious inflammation is recognized to play decisive roles at different stages of tumor development, including initiation, promotion, malignant conversion, invasion, and metastasis $[28,52]$. The actions of the immune system against tumors in progress can be referred to as the cancer immunoediting process, which is composed of three distinct phases: elimination, equilibrium and escape. During the elimination phase and the equilibrium phase the immunological response is able to prevent tumor progression. In contrast, during the escape phase acquired adaptations of malignant cells and the host immune system response allow for expansion of the tumor cell population [94]. By acting as an intrinsic effector mechanism and by forming a functional bridge between the innate and the adaptive immune system, the complement system is an integral component of the antitumor immune response [94]. Complement activation following recognition of damage-associated molecular patterns (DAMPs) expressed by tumor cells, or improper regulation, allow for a potent anti-tumor response [37]. The potent antitumor response by complement has been utilized for antibody-based cancer immunotherapies by eliciting complement-dependent cytotoxicity, exemplified by the use of rituximab and ofatumumab in the treatment of B cell lymphomas and chronic lympocytic leukaemia, respectively [89]. However, the complement system also shows another face. Recent pre-clinical cancer models showed that the activated complement system contributes to a tumor facilitating micro-environment [1]. This adverse capacity seems to be a consequence of imbalanced, rather than physiological, complement activation [74]. Various studies have reported significant reductions of orthotopic tumor growth following complement system inhibition within the cascade [74]. Further, diverse complement effectors are implicated in other cancer-related phenomena as sustained proliferative signaling, angiogenesis and invasion and metastasis [33, 74].

Contributory to treatment resistance of glial neoplasms is the presence of glioma stem-like cells (GSCs) [85]. GSCs reside in specific anatomical niches within the tumor and propagate glioma repopulation by converting into either a differentiated tumor cell, or a new cancer stem cell [46]. The maintenance of GSCs requires specific intrinsic factors within the cells and various paracrine cues from adjacent cells [46]. The complement system represents an as yet unidentified effector in GSC maintenance, and unraveling its interplay will reveal new targets for therapeutic intervention.

\section{Complement and GSC maintenance: Intrinsic regulation}

Factors that are involved in GSC maintenance comprise of metabolic, genetic and epigenetic regulatory mechanisms [90]. Although the mechanisms underlying GSC plasticity are largely unknown, several intrinsic regulatory mechanisms are known to be involved in reprogramming 
differentiated GBM cells into stem-like cells. Among these are Sex Determining Region Y -Box 2 (SOX-2) [88], signal transducer and activator of transcription 3 (STAT-3), octamer-binding transcription factor 4 (OCT-4) and mammalian target of rapamycin (mTOR) signaling [23, 82]. The GSCs maintain their multipotent state through autocrine stimulation of the C3a- and C5a-receptors on the plasma membrane by secretion of alternative pathway C3-convertase components (C3, factor D and factor B) and subsequent extracellular cleavage of $\mathrm{C} 3$, as observed in resting T-cells (Fig. 2) [87]. The C3 and C5 convertases (Fig. 1) are responsible for the release of their respective bioactive fragments C3a and C3b, and C5a and C5b. The anaphylotoxins C3a and C5a signal through the $\mathrm{G}$ protein coupled receptors $\mathrm{C} 3 \mathrm{aR}$ and $\mathrm{C} 5 \mathrm{aR}(\mathrm{CD} 88)$ respectively. Interaction of several downstream signal transduction pathways followed by $\mathrm{C} 3 \mathrm{aR}$ and $\mathrm{C} 5 \mathrm{aR}$ activation with recognized GSC regulatory mechanisms effectors may therefore aid to GSC maintenance. Figure 2 presents a schematic overview of the interaction of autocrine derived complement with GSC regulatory mechanisms. C3a-C3aR interaction activates STAT-3 and causes an increase of Wnt2b and SOX-2 expression in a serine protease MAPK dependent fashion, as was shown in a model of retinal regeneration [36]. C5aR1 activation contributes to the maintenance of pluripotency of OCT-4 positive human induced pluripotent stem cells (hPSC) through extracellular signal-regulated protein kinases 1 and 2 (ERK1/2) activation [35]. In vitro administration of recombinant $\mathrm{C} 5 \mathrm{a}$ to $\mathrm{C} 5 \mathrm{aR}$ expressing gastric cancer cells promotes the activation of PI3K/Akt and downregulates p21 activation [11]. Inhibition of p21 is a key mechanism of GSC self-renewal and prevention of differentiation [99].

Further, complement C3 activation is not limited to the extracellular space because intracellular C3 activation is an ubiquitous event within human cells [50]. Resting T-lymphocytes contain intracellular pools of $\mathrm{C} 3$ that are activated by cysteine protease cathepsin- $\mathrm{L}$. This 'tonic' intracellular $\mathrm{C} 3 \mathrm{a}$ generation engages $\mathrm{C} 3 \mathrm{aR}$ present on lysosomes and sustains the basal mammalian target of rapamycin (mTOR) activation required for T-cell survival [50]. Activation of the PI3K/Akt/mTOR signaling cascade is involved in GSC phenotype maintenance [18]. In addition, GBM tissue shows the profound presence of cathepsin L, which has been shown to negatively affect apoptosis and promotes invasion [104]. Intracellular $\mathrm{C} 3 \mathrm{a}$ activation by cathepsin-L may provide for an as yet unidentified additional intrinsic GSC effector mechanism. Noteworthy is the critical role of autocrine derived C5a-C5aR1 signalling in affecting the

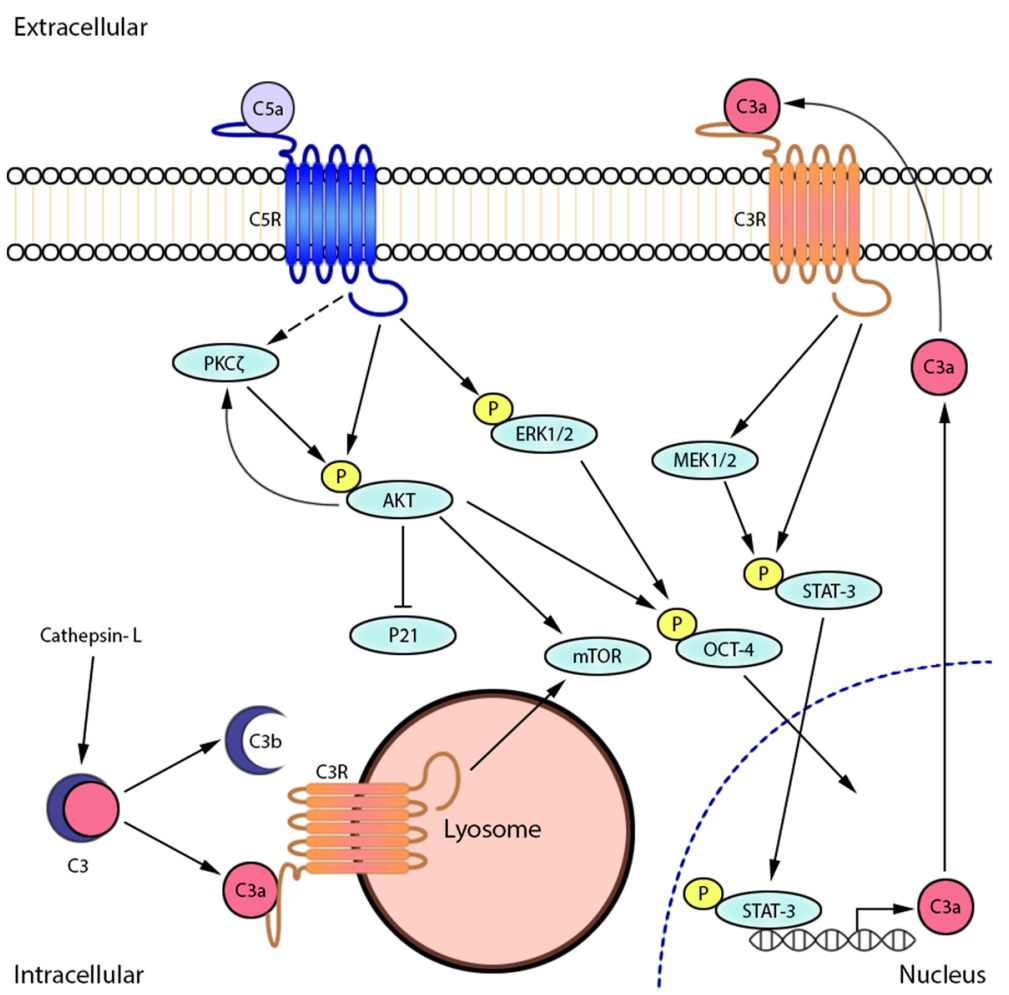

Fig. 2 Proposed interaction of complement C3a and C5a with GSC regulatory mechanisms. C5a-C5aR interaction activates PI3K/Akt/mTOR signaling and PKC but suppresses p21 with subsequent OCT-4 activation. Intracellular activation of C3a by cathepsin-L may occur, thereby sustaining basal mTOR activation. Either intracellular or extracellular derived C3a phosphorylates STAT-3 and causes an increase of sOX-2 expression 
fate of Neural Progenitor Cells (NPCs). C5a was found actively secreted within neural rosettes [16]. Atypical protein kinase $\mathrm{C}$ zeta (PKC) ) dependent C5a-C5aR1 signaling regulates the apicobasal polarity of the NPC, thereby maintaining symmetrical self-renewing cell division [16]. PKCל inhibition reverses C5a-C5aR induced $\mathrm{p} 42 / 44$ phosphorylation (ERK) and attenuates the mitotic activity of NPCs [16]. PKC $\zeta$ is overexpressed in GBM cells and its downregulation inhibits in vitro migration and invasion of GBM cells. Another mechanism through which the GSC could generate C5 in order to self-activate $\mathrm{C} 5 \mathrm{aR}$ is by expressing cell membrane-bound serine protease, as was found in different cancer cell types [62].

\section{Complement and GSC maintenance}

The neuropil constitutes the extracellular matrix of the brain in which endothelial and perivascular cells, microglia, tumor-associated macrophages and non-neoplastic astrocytes are present and networks of cytokines and growth factors are active [32]. Together with neoplastic cells the microenvironment coalesces into the tumor mass. GSC are enriched in areas of hypoxia, in perivascular niches and at the invasive edge of the tumor [46]. A graphical representation of the various cells involved is provided in Fig. 2. The actions of the complement factors within the various glioma niches are summarized in Table 1.

\section{Hypoxic niche}

The inadequate neo-angiogenesis in GBM results in hypoxic areas within the tumor. The neoplastic cells respond to low oxygen levels by the expression of members of the hypoxia inducible factor (HIF) family of transcriptional factors [49]. HIFs are upregulated in GSC and its forced expression induces a stem-cell like phenotype in glioma cells [49]. Transcriptional targets of HIFs include angiogenic genes like Vascular Endothelial Growth Factor (VEGF) as well as stem cell markers [49]. Areas of hypoxia optimally accommodate complement activation as provide for damage-associated molecular patterns (DAMPs) that are recognized by C1q. Hypoxic conditions induce (HIFdependent) down-regulation of complement regulatory genes CD55, CD46 and factor $\mathrm{H}$ and upregulate C3, C3a and C3aR and enhance C3a-C3aR engagement $[27,66]$. The constituents of the complement system have been identified to interact with HIF associated signaling pathways and may therefore act as an additional effector mechanism in HIF dependent GSC survival, self-renewal and tumor growth. Firstly, the complement system contributes to facilitate HIF transcription through STAT-3 activation that is critical for the transcription of HIF- $1 \alpha$ in GSCs and tumor-associated myeloid cells [69]. The production of reactive oxygen species, as a result of overexpression of nicotinamide adenine dinucleotide phosphate oxidase 4 (NOX-4), was identified as the molecular mechanism underlying hypoxia-induced STAT-3 activation in GBM cells [103]. In a model of renal ischemia/reperfusion injury, oxidative stress induces an increased expression of NOX-4 in tubular cells and NOX-2 infiltrating monocytes and myeloid dendritic cells [84]. This effect is dramatically reduced after the administration of the complement 1-inhibitor (C1-INH). In vitro administration of C3a to cultured proximal tubular cells induces NOX-4 expression regardless of hypoxic conditions [84].

Secondly, through C3aR and C5aR interaction on the GSC, complement may provide for additional signal transduction pathways for PI3K- or mitogen-activated protein kinase (MAPK)/ERK1/2-dependent HIF-1 $\alpha$ protein translation $[68,69]$. HIF- $1 \alpha$ and the components of the complement cascade converge at the level of the Notch signaling pathway. Notch activation restricts glioma cell differentiation and stimulates astrocytes into a neural stem-like cell state [69]. HIF-1/2 $\alpha$ driven GSC maintenance requires Notch signaling [69]. In resting T-cells, CD46 sequesters the Notch ligand Jagged-1, thereby preventing the interaction between Jagged-1 and Notch that activates T-cells [48]. Hypoxia-mediated downregulation of the expression of CD46 or CD46-C3b interaction following complement activation may allow for Notch-Jagged-1 interaction. A direct contribution of CD46 downregulation in maintaining the undifferentiated state of the GSC remains to be elucidated. C3a inhibits SDF-1 $\alpha$ induced neuronal differentiation of NPCs through ERK1/2 phosphorylation regulation [83]. SDF- $1 \alpha$ is a HIF- $1 \alpha$ target gene in GBM cells [22]. Importantly, SDF- $1 \alpha$ induces recruitment of bone-marrow derived CD45+ myeloid cells, endothelial and pericyte progenitor cells to GBM [22].

Lastly, HIF- $1 \alpha$ modulated, Wnt/ $\beta$-catenin activation has been identified to stimulate GSC differentiation and therefore promotes a less-aggressive, neuronal tumor phenotype. Subsequent $\beta$-catenin mediated Notch inhibition further allows for GSC differentiation [71]. The role of Wnt activation in regulating the GSC state remains controversial as many reports claim that Wnt activation promotes GSC maintenance and expansion [42]. C1q is an activator of canonical Wnt signalling through binding with the Fz-receptor and subsequent induction of $\mathrm{C} 1 \mathrm{~s}$ dependent cleavage of low-density lipoprotein receptor-related protein 6 (LRP6) [61]. Intriguingly, C1q-induced activation of Wnt signalling attenuates the proliferation of muscle stem cells [61].

\section{Perivascular niche}

As a result of vigorous and abnormal angiogenesis, local regions of hypoxia develop with subsequent complement activation, facilitating complement mediated GSC regulation. The actions of the complement system extend into the perivascular niche, where GSC survival and 
Table 1 Complement protein in the GBM tumor

\begin{tabular}{|c|c|c|c|}
\hline Complement proteins & Niche & Mechanism & Proposed effect \\
\hline \multirow[t]{6}{*}{$\mathrm{C} 1 \mathrm{q}$} & GSC & Wnt activation & Stimulate GSC differentiation \\
\hline & Perivascular & Priming SDF-1 gradient & GSC migration \\
\hline & Perivascular & gC1qR interaction & $\begin{array}{l}\text { Potentiate tumor cell invasiveness, } \\
\text { chemoattractant }\end{array}$ \\
\hline & Perivascular & $\begin{array}{l}\text { CC19R interaction (IL-8, } \\
\text { MCP-1 and IL-6 secretion) }\end{array}$ & GSC migration \\
\hline & Microenvironment & GAM-M2 induction & Immunosuppression \\
\hline & Invasive & gClqR (Bradykinin induction) & Tumor cell invasiveness \\
\hline MBL & Microenvironment & GAM-M2 induction & Immunosuppression \\
\hline C3 & Microenvironment & MDSC recruitment & Immunosuppression \\
\hline \multirow[t]{2}{*}{ C3b } & Microenvironment & Treg induction (ligand for CD46) & Immunosuppression \\
\hline & Microenvironment & GAM-M2 induction & Immunosuppression \\
\hline \multirow[t]{5}{*}{$\mathrm{C} 3 \mathrm{a} / \mathrm{C} 3 \mathrm{aR}$} & Hypoxic & STAT-3 activation & GSC maintenance \\
\hline & GSC & mTOR activation & GSC maintenance \\
\hline & Hypoxic & NOX-4 activation, (STAT-3, HIF-a) & GSC maintenance \\
\hline & GSC & sOX-2 activation & GSC maintenance \\
\hline & Microenvironment & Chemotaxis immune cells & \\
\hline \multirow[t]{2}{*}{ CD46 } & Hypoxic & Jagged-1-Notch disruption & GSC maintenance \\
\hline & Perivascular & & \\
\hline \multirow[t]{13}{*}{$\mathrm{C} 5 \mathrm{a} / \mathrm{C} 5 \mathrm{aR}$} & Invasive nice & PKC activation & Potentiate tumor cell invasiveness \\
\hline & GSC & $\mathrm{PI} 3 \mathrm{~K} / \mathrm{Akt} / \mathrm{mTOR}$ & GSC maintenance \\
\hline & GSC & P21 inhibition & GSC maintenance \\
\hline & GSC & OCT-4 expression & GSC maintenance \\
\hline & Perivascular & MMP-9, MT1-MMP activation & Increase tumor cell invasiveness \\
\hline & Perivascular & MCP-1 secretion & Increase tumor cell invasiveness \\
\hline & Perivascular & TGF- $\beta$ & $\begin{array}{l}\text { GSC differentation into vascular } \\
\text { pericytes }\end{array}$ \\
\hline & Perivascular & NO secretion (iNOS/eNOS induction) & GSC maintenance \\
\hline & Perivascular & VEGF expression & Vascular tube formation \\
\hline & Microenvironment & Chemotaxis immune cells & \\
\hline & Microenvironment & Treg induction (High concentration) & Immunosuppression \\
\hline & Microenvironment & GAM-M1 activation (balanced C activation) & Anti-tumor response \\
\hline & Microenvironment & MDSC recruitment (ROS) & Immunosuppression \\
\hline C5b-C9 & Perivascular & bFGF release & GSC dedifferentiation \\
\hline
\end{tabular}

angiogenesis are mediated. In the adult mammalian brain, neuronal stem cells reside in two germinal niches of which the subventricular zone is highly vascularized. Adult stem cells lie in close proximity to the vasculature, where communication occurs through direct cell-cell interactions and soluble secreted cues [81]. In contrast to germinal niches, where the rate of stem cell proliferation is low, the perivascular niche within GBM contributes to the generation of the GSCs and tumor growth [9]. Besides endothelial cells (EC) and GSCs, major cell types that have been recognized to reside in the perivascular niche include pericytes, immune cells, fibroblasts and astrocytes, all of which provide an additional biological source of complement proteins $[9,93]$. The complement system establishes an active interplay with the perivascular niche constituents and GSCs and fulfills an active role in the migration of GSC and promotes angiogenesis.

Several components of the (activated) complement system are powerful chemoattractants attracking blood borne cells and GSCs to the perivascular niche [75]. The complement system potentiates the migration of GSC towards the perivascular niche just like it does to mesenchymal stem cells (MSCs), NPCs and hematopoietic stem/progenitor cells (hPSC). In GBM, GSCs move 
towards the tumor vasculature and engage in cell-cell contact [9]. The interaction of Stromal Cell-Derived Factor 1 (SDF1) with its receptor C-X-C Motif Chemokine Receptor 4 (CXCR4) is operative to guide the tumor cells to the peri-endothelial space [72]. C1q primes chemotactic SDF-1-dependent migration of human umbilical cord blood derived- Mesenchymal Stem Cells (MSC), in part by upregulating the expression of CXCR4 and through interaction with its globular heads binding receptor (gC1qR), which is ubiquitously expressed [70]. The activated complement system potentiates the SDF1-CXCR4 chemotaxis, independent of C3aR, as has been observed in hematopoietic stem/progenitor cells (HSPCs) [38]. C3a modulates concentration-dependent SDF1-CXCR4 induced migration of NPCs [83]. C5a attracts MSCs in a C5aR dependent fashion and its degradation product $\mathrm{C} 5 \mathrm{a}_{\text {desArg }}$ causes an increased secretion of MMP-9 and MT1-MMP, creating a highly proteolytic microenvironment in favor of cell-migration [79]. In addition, IL- 8 secreted by ECs stimulates GSC migration and maintains its stemness properties, in part by upregulating the expression of its cognate receptors CXCR1 and CXCR2 [39]. The interaction of C1q with its receptor present on the $\mathrm{EC}(\mathrm{cClqR})$ initiates the release of IL-8, macrophage chemoattractant protein-1 (MCP-1) and IL-6, that contribute to the homing of GSCs and MSCs [92, 97]. IL-8 mediated GSC homing and maintenance is amplified by C5a as observed in whole blood cells and in human dermal microvascular endothelial cells (HVEC-d) [97]. Lastly, C5a contributes to GSC migration by increasing the expression of MCP-1/CCL2, as observed in HVEC-d in a dose dependent matter [102].

\section{Complement modulated Perivascular niche-GSC interaction}

GSCs form intimate contacts along the length of the endothelial tube, essential for their survival and inducing secretion of soluble factors by ECs that keep the GSCs in an undifferentiated state [80]. Several pathways constitute EC orchestrated GSC regulation, including the transforming growth factor- $\beta$ (TGF- $\beta$ ) pathway [80]. EC-derived TGF- $\beta$ induces the differentiation of GSC into pericytes that contribute to vascular formation in GBM [12]. Crosstalk of TGF- $\beta$ signaling and complement activation is observed in various cells. C5a has been shown to upregulate TGF- $\beta$ transcript expression, and vice-versa TGF- $\beta$ upregulates the expression of C5aR [29]. Further, TGF- $\beta$ and C5a signaling converge downstream at the level of SMAD independent pathways including, PI3K/AKT/mTOR and MAPK/ERK1/2 signaling pathways $[77,105]$. A second pathway through which the GSC phenotype is maintained is the nitric oxide (NO) signaling [10]. The biological source of $\mathrm{NO}$ is EC-derived by the expression of endothelial NO synthase (eNOS) or alternatively, through the expression of inducible
NOS (iNOS) by the GSC [10]. Activation of eNOS requires phosphorylation of AKT, suggestive of a contributory role for the activated complement system [21]. The complement system mediates the expression of iNOS and NO levels as shown in models of gastrointestinal ischemia by inhibition of C3 and C5 [57]. Lastly, EC derived basic Fibroblast Growth Factor (bFGF) induces the reversion of differentiated GBM cells [25]. However, the underlying mechanism resulting in functional expression of bFGF remains poorly defined, given that hypoxia does not induce bFGF expression in human vascular smooth muscles cells [7]. Interestingly, small amounts of C5b-9 (membrane attack complex) releases bFGF from human umbilical vein endothelial cells (HVEC) [4]. Active and inactive forms of C1s are found to form aggregates with bFGF, thereby reducing its activity [76].

\section{The complement system influences GSC mediated angiogenesis}

Indications for the close interaction of GSC and endothelial cells emerged from the finding that xenotransplanted tumors derived from GSCs were characterized by widespread angiogenesis that was not encountered in their non-GSC counterparts [3]. GSCs secrete VEGF and treatment with bevacizumab blocks the pro-angiogenic effects of VEGF by hampering microvascular endothelial cell migration and vascular tube formation and inhibiting the growth and vascularity of GSC derived xenotransplants [3]. Bioactive complement products have been identified as important effectors in pathological neovascularization in age-related macular degeneration (ARMD), diabetic retinopathy, and retinopathy of prematurity [100]. Interaction of C5a with its receptor C5aR1 induces VEGF expression in a dose-dependent matter in retinal pigmented epithelium (RPE) in-vivo and in-vitro [15]. The induction of oxidative stress in RPE cells reduces the surface expression of DAF, CD55 and CD59 and impairs complement regulation at the level of factor $\mathrm{H}$, resulting in complement activation and complement-dependent VEGF expression [91]. Consequently, inhibiting the AP using a recombinant factor $\mathrm{H}$ reduces the expression of VEGF and subsequent angiogenesis in a mouse model of choroidal neovascularization [91]. Conversely, the inhibition of VEGF causes a decrease of the complement inhibitory proteins (CIPs) factor $\mathrm{H}, \mathrm{CD} 46$ and CD59 in human RPE-cells and glomerular endothelial cells through VEGFR2/PKC- $\alpha / C R E B$ signaling [44]. These observations imply that VEGF protects neo-angiogenesis by local inhibition of the complement system. It remains undetermined whether complement activation directly contributes to VEGF expression or VEGF suppresses complement activation through CIP induction. In a mouse model of ovarian cancer, C3 and C5aR were shown to be closely involved in neo-angiogenesis [63]. Tumors derived from partial C3, $\mathrm{C} 5 \mathrm{aR}$ and complete $\mathrm{C} 5 \mathrm{aR}$ knock out mice displayed 
decreased microvascular density compared to their WT-littermates [63]. Additional in vivo assays showed significant impairment of angiogenesis for complete C3 and $\mathrm{C} 5 \mathrm{aR}$ knock-out mice. Interestingly, direct functional effect of C5a comparable to VEGF-A on tube formation of endothelial cells was also observed. This effect was found to be reversible using the $\mathrm{C} 5 \mathrm{aR}$ inhibitor PMX-53. PMX-53 also significantly impaired VEGF $_{165}$ mediated HMEC tube formation [63]. In addition to C3 and C5aR, microvascular density was significant decreased in tumors in $\mathrm{C} 1 \mathrm{q}$ deficient mice bearing a syngeneic B16 melanoma compared to their WT-littermates [8].

\section{Complement and immune cell crosstalk in the perivascular niche}

Activation of the complement system by means of C3a and $\mathrm{C} 5 \mathrm{a}$ plays an important role in the inflammatory process by recruiting immune cells such as mast cells, monocytes, macrophages, neutrophils, MDSCs and adaptive immune cells including $T$ cells [75]. The BBB consists of highly specialized endothelial cells that communicate with pericytes and astrocytes to protect the CNS from the chemical variations in the bloodstream, and establishes a strictly controlled interface for immune cell trafficking. In GBM the BBB's integrity is disrupted due to the abnormal tumor microvasculature, resulting in an increased vascular permeability and consequently, an increase in immune cell infiltration including monocyte-derived cells, microglia and T-lymphocytes $[19,24]$. C5a/C5aR neutralization alleviates the BBB breakdown in models of traumatic brain injury and systemic lupus erythematodus and it is likely that the activated complement system also affects the BBB in GBM, with possible consequences for the passage of immune cells [40].

\section{Lymphocytic infiltration and PD-1}

In glioma, tumor infiltrating lymphocytes (TILs) consisting of CD4+ and CD8+ cells are present [65]. Glioma TILs show a predominant regulatory T-cell population (CD4 + CD25 + Foxp3+) [65]. Regulatory $\mathrm{T}$ cells (Tregs) are believed to be the primary regulators of immunosuppression in the glioma microenvironment [65]. The proportions of CD3+ and CD8+ over Foxp3+ cells reportedly correlate with the clinical course of GBM patients [78]. The activated complement system by means of CD46 may account for an increased proportion of Tregs. The C3 cleavage fragment, C3b, is a natural ligand for CD46 on T cells. Stimulation of naïve CD4+ T cells with anti-CD46 monocolonal antibodies $(\mathrm{mAb})$ or $\mathrm{C} 3 \mathrm{~b}$ dimers in the presence of IL-2 induces a differentiation towards a IL-10 producing type 1 regulatory $\mathrm{T}$ cell $(\mathrm{Tr} 1)$ [45]. However, CD4+ Foxp3+ regulatory $\mathrm{T}$ cells present in GBM are predominantly thymus derived (tTregs) rather than peripheral induced IL-10 producing regulatory $\mathrm{T}$-cells [95]. In the presence of CD46 stimulation, cell contact-mediated tTreg function is impaired [47]. Instead, tTregs differentiate to IL-10 secreting $\operatorname{Tr} 1$ cells [47]. In several human cancers a potent immunosuppressive subpopulation of IL-10 producing Tregs has been identified and these Tregs suppress CD8+ T-cell effector functions which is associated with poor survival [64].

In models of melanoma and non-small cell lung cancer combined with genetic ablation or mAb blocking of programmed death 1/programmed death ligand 1 (PD-1/ PD-L1) and C3aR appears to be more effective in restraining tumor growth than only blocking PD-1 therapy alone [2]. In glioma, the expression of PD-L1 is correlated with glioma grade and has been identified as a negative prognostic factor. Recently, therapeutic blockade of PD-1 in the GL-261 murine glioma model induced an impressive prolonged survival, with TILs showing a shift towards CD8+ T cells [20]. The dual role of complement activation in the tumor micro-environment was illustrated by tumor progression in tumor-bearing mice with either high- or low C5a-producing syngeneic lymphoma cells [30]. High C5a producing tumors showed a significant increased tumor progression associated with an overall decrease CD4+ and CD8+ T cells in the tumor [30]. Further, it was shown that in vitro polarization of CD4+ cells is observed to be C5a concentration dependent. A low C5a concentration promotes Th1 cell differentiation while high concentrations (> $500 \mathrm{ng} / \mathrm{ml}$ ) promotes Treg induction [30]. Taken together, imbalanced complement activation may be associated with an immunosuppressive micro-environment and is therefore contributory to tumor progression.

\section{Glioma associated microglia and macrophages (GAMs)}

Glioma associated microglia and macrophages (GAMs) are considered to be the most prominent glioma-infiltrating immune cells, constituting up to $30 \%$ of all immune cells within the tumor microenvironment. GAMs are recruited into the tumor microenvironment through various glioma derived factors that contribute to polarization from a tumor-suppressive to a tumor-promoting phenotype. Activated complement factors may contribute to the constant recruitment of GAMs to the tumor micro-environment, either directly, or through interactions with glioma factors, and influence their polarization. Several factors have been recognized to attract GAMs to the tumor environment, among which are MCP-1 and SDF-1 [31]. C1q and C5a have been shown to potentiate the actions of these chemokines $[67,70]$. Upon lipopolysaccharide (LPS), IFN $\gamma$, or C3a and C5a induced activation (M1) GAMs produce inflammatory mediators, phagocytose tumor cells, present antigens to immune cells and induce a T-cell response [34]. In contrast, GAMs activated through factors such as CSF-1, 
IL-10, TGF- $\beta$ and the complement opsonins C1q and C3b acquire a pro-tumorigenic phenotype (M2) which include promoting and facilitating immunosuppression, glioma proliferation and invasiveness [98]. Unbalanced complement activation induces Il-10 and TGF- $\beta$ expression, thereby promoting a pro-tumorigenic phenotype [29, 47]. Within the scope of autoimmunity the complement opsonins $\mathrm{C} 1 \mathrm{q}$ and $\mathrm{MBL}$ regulate macrophage polarization towards a M2 macrophage phenotype [5, 26].

\section{Myeloid-derived suppressor cells (MDSC)}

Myeloid-derived suppressor cells (MDSCs) are a heterogeneous population of cells containing myeloid cells in various differentiation stages. MDSCs are found to be significantly increased in the peripheral blood of glioblastoma patients [73]. MDSCs are believed to elicit distinct immunosuppressive actions within the glioma micro-environment including generation of oxidative stress through the production of ROS and thereby inducing T-cell inhibition [24]. Intriguingly, in a TC-1 syngeneic model of cervical cancer in mice, pharmacological inhibition of $\mathrm{C} 5 \mathrm{aR}$ resulted in an increase in CD8+ T-cell infiltration along with deceleration of tumor growth comparable to the effects of paclitaxel [53]. C5a mediated suppression of the antitumor CD8+ T-cell response is associated with an increase of MDSC in the tumor microenvironment and a subsequent increase in ROS production [53]. In a syngeneic mouse model for lung cancer, MDSCs appeared to be reduced in a subpopulation analysis of splenocytes after C5aR blockade [14]. Concordantly, in a murine model of ovarian cancer C3 silencing increases the number infiltrating CD8+ T-cells infiltrating the tumor by 10-fold and reduced the number of MDSCs by $80 \%$ [13]. However, the observed reduction in tumor growth was found to be independent on the number of CD8+ T-cells [13].

\section{Invasive niche}

High-grade gliomas show aggressive invasiveness in two compartments: the perivascular space and the brain parenchyma [17]. The bradykinin and the SDF-1/CXCR4 axis act as a chemoattractant that guide glioma cells towards blood vessels [58]. The bradykinin-forming cascade and the

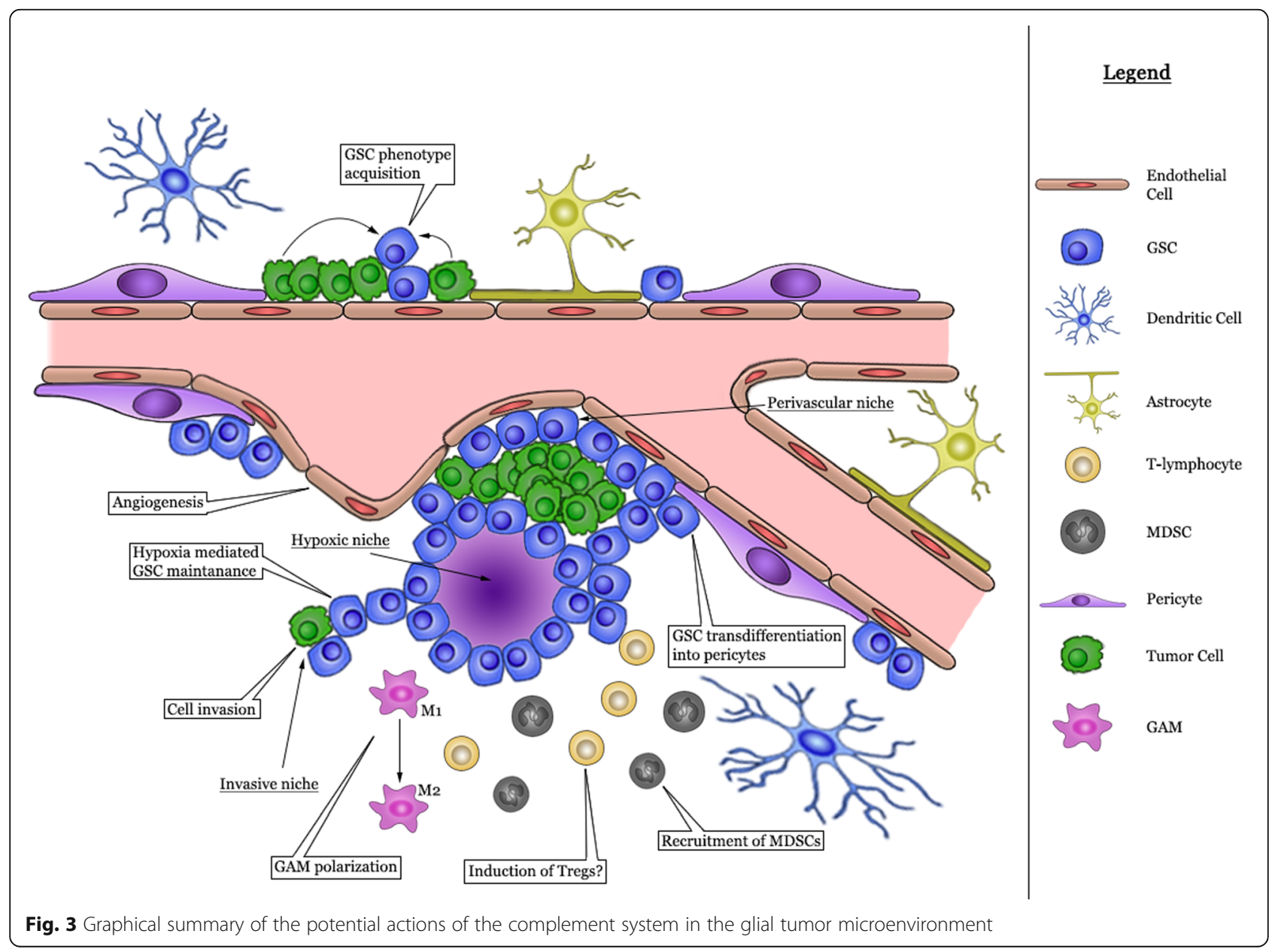


classical complement pathway share many elements, including cross-activation, shared binding proteins and control mechanisms [43]. $\mathrm{C} 1$ inhibitor ( $\mathrm{C} 1 \mathrm{INH})$ inhibits the bradykinin-forming cascade at several levels: its local absence at the glioma invasive edge may further initiate the classic complement cascade by activating $\mathrm{C} 1 \mathrm{r}$ [43]. Vice-versa, the presence of the ubiquitously expressed receptor for the globular head of $\mathrm{Clq}(\mathrm{gClqR})$ allows for bradykinin production on the endothelial cell surface [43]. The activated complement system further stimulates glioma cell migration through facilitating local degradation of extracellular matrix proteins. In $\mathrm{C} 5 \mathrm{a}$ R expressing colon and bile duc cancer cells C5a enhances cell invasiveness by increasing the expression of several matrix metalloproteinases (MMPs), including MMP-1 and MMP-9 in C5aR expressing colon and bile duct cancer cells [62]. Soluble C5b-9, which is as a pro-inflammatory mediator, induces MMP-2 expression by microglia upon activation [101]. The molecular regulation of MMP-2 and MMP-9 is poorly characterized. The activated complement system signaling may provide an alternative mechanism for the NF- $\mathrm{kB}$ mediated overexpression of MMP-2 and MMP-9 in glioma cells by means of C5a-C5aR [86]. C1q may activate the canonical Wnt/ $\beta$-catenin signaling pathway, which increases MMP-2 and MMP-9 expression by glioma cells [41].

\section{Conclusion remarks and future directions}

A wide variety of molecular pathways that are characteristic of the aggressive nature of GBM are known to be induced or modulated by the activated complement system (Table 1 and Fig. 3). The unbalanced activation in the tumor microenvironment may suppress the antitumor inflammatory response. There is increasing data that the complement system could serve as an unidentified intrinsic and extrinsic regulatory mechanism for GSC maintenance, thereby supporting treatment resistance. The activated complement system may contribute to evade the immune response, activate invasion and induce angiogenesis. Because several tumor promoting pathways are activated by complement the elucidation of the role of complement activation is necessary to discover new targets for therapy in malignant glioma.

\footnotetext{
Abbreviations

AP: Alternative Pathway; BBB: Blood Brain Barrier; bFGF: basic Fibroblast Growth Factor; C1-INH: C1-inhibitor; C3aR: C3a Receptor; C5aR1: C5a Receptor-1; C5b-9: Membrane Attack Complex; cC1qR: collagen C1q Receptor (Calreticulin); CNS: Central Nervous System; CREB: Cellular Transcription Factor; CSF 1: Colony Stimulating Factor 1; CXCR1: C-X-C Motif Chemokine Receptor 1; CXCR2: C-X-C Motif Chemokine Receptor 2; CXCR4: C-X-C Motif Chemokine Receptor 4; DAMP: Damage-Associated Molecular Pattern; EC: Endothelial Cells; eNOS: endothelial Nitric Oxide synthase; ERK1/2: Extracellular-signal regulated kinases; Fz: Frizzled; GBM: Glioblastoma Multiforme; gC1qR: Globular C1q Receptor; GSC: Glioma Stem-like Cell; HIF: Hypoxia Inducible Factor; HMEC: Human Mammary Epithelial Cells; hPSC: human induced Pluripotent Stem Cells; HVEC: Human Umbilical Vein Endothelial Cells; HVEC-d: Human Dermal Microvascular Endothelial Cells; IFNץ: Interferon- $\gamma ;$ LPS: lipopolysaccharide; LRP6: Low-
}

density lipoprotein receptor-related protein 6; MAPK: Mitogen-Activated Protein Kinase; MBL: Mannose Binding Lectin; MCP-1: Macrophage Chemoattractant Protein-1; MMP-9: Matrix metallopeptidase 9; MSC: mesenchymal stem cells; MSDC: Myeloid-Derived Suppressor Cell; MT1MMP: Membrane-Type 1 Matrix MetalloProteinase; mTOR: mammalian target of rapamycin; NO: Nitric Oxide; NOX-2: Nicotinamide adenine dinucleotide phosphate OXidase 2; NOX-4: Nicotinamide adenine dinucleotide phosphate OXidase 4; NPC: Neural Progenitor Cell; OCT-4: Octamer-Binding Transcription Factor-4; PD-1: Programmed Cell Death protein 1; PD-L1: Programmed Cell Death ligand 1; PI3K: Phosphatidylinositol 3-kinase; PKC-a: Protein kinase Ca; PKCZ: Protein Kinase C zeta; ROS: Reactive Oxygen Species; SDF-

1a: Stromal Cell-Derived Factor 1a; SOX-2: Sex Determining Region Y -Box 2; STAT-3: Signal Transducer and Activator of Transcription-3; TGF-

$\beta$ : Transforming Growth Factor- $\beta$; TIL: Tumor Infiltrating Lymphocytes; VEGF: Vascular Endothelial Growth Factor; VEGFR2: Vascular Endothelial Growth Factor Receptor 2; Wnt: Wingless-related integration site

\section{Authors' contributions}

TB conceived of the presented idea. TB wrote the manuscript with support from JK, LA, RW, DM and PH. PS and JK supervised the project. All authors read and approved the final manuscript.

\section{Competing interest}

The authors whose names are listed above certify that they have no affiliations with or involvement in any organization or entity with any fi nancial interest (such as honoraria; educational grants; participation in speakers' bureaus; membership, employment, consultancies, stock ownership, or other equity interest; and expert testimony or patent-licensing arrangements), or non-financial interest (such as personal or professional relationships, affiliations, knowledge or beliefs) in the subject matter or materials discussed in this manuscript.

\section{Publisher's Note}

Springer Nature remains neutral with regard to jurisdictional claims in published maps and institutional affiliations.

\section{Author details}

${ }^{1}$ Department of Bioinformatics, Erasmus University Medical Center, Wytemaweg 80, 3015, GE, Rotterdam, The Netherlands. ²Department of Neurosurgery, Maastricht University Medical Center, P. Debyelaan 25, 6229, HX, Maastricht, The Netherlands. ${ }^{3}$ Department of Pathology, Erasmus University Medical Center, Wytemaweg 80, 3015, GE, Rotterdam, The Netherlands. ${ }^{4}$ Department of Internal Medicine, Erasmus University Medical Center, Wytemaweg 80, 3015, GE, Rotterdam, The Netherlands. ${ }^{5}$ Department of Immunology, Erasmus University Medical Center, Wytemaweg 80, 3015, GE, Rotterdam, The Netherlands.

Received: 13 July 2018 Accepted: 29 August 2018

Published online: 12 September 2018

\section{References}

1. Afshar-Kharghan V (2017) The role of the complement system in cancer. J Clin Invest 127:780-789. https://doi.org/10.1172/jci90962

2. Ajona D, Ortiz-Espinosa S, Moreno H, Lozano T, Pajares MJ, Agorreta J, Bertolo C, Lasarte JJ, Vicent S, Hoehlig K et al (2017) A combined PD-1/C5a blockade synergistically protects against lung Cancer growth and metastasis. Cancer discovery 7:694-703. https://doi.org/10.1158/2159-8290.cd-16-1184

3. Bao S, Wu Q, Sathornsumetee S, Hao Y, Li Z, Hjelmeland AB, Shi Q, McLendon RE, Bigner DD, Rich JN (2006) Stem cell-like glioma cells promote tumor angiogenesis through vascular endothelial growth factor. Cancer Res 66:7843-7848. https://doi.org/10.1158/0008-5472.can-06-1010

4. Benzaquen LR, Nicholson-Weller A, Halperin JA (1994) Terminal complement proteins C5b-9 release basic fibroblast growth factor and platelet-derived growth factor from endothelial cells. J Exp Med 179:985-992

5. Bohlson SS, O'Conner SD, Hulsebus HJ, Ho MM, Fraser DA (2014) Complement, $\mathrm{clq}$, and c1q-related molecules regulate macrophage polarization. Front Immunol 5:402. https://doi.org/10.3389/fimmu.2014.00402

6. Bouwens TA, Trouw LA, Veerhuis R, Dirven CM, Lamfers ML, Al-Khawaja H (2015) Complement activation in glioblastoma multiforme pathophysiology: evidence from serum levels and presence of complement activation products in tumor tissue. J Neuroimmunol 278:271-276. https://doi.org/10. 1016/j.jneuroim.2014.11.016 
7. Brogi E, Wu T, Namiki A, Isner JM (1994) Indirect angiogenic cytokines upregulate VEGF and bFGF gene expression in vascular smooth muscle cells, whereas hypoxia upregulates VEGF expression only. Circulation 90:649-652

8. Bulla R, Tripodo C, Rami D, Ling GS, Agostinis C, Guarnotta C, Zorzet S, Durigutto P, Botto M, Tedesco F (2016) Clq acts in the tumour microenvironment as a cancer-promoting factor independently of complement activation. Nat Commun 7:10346. https://doi.org/10.1038/ncomms10346

9. Calabrese C, Poppleton H, Kocak M, Hogg TL, Fuller C, Hamner B, Oh EY, Gaber MW, Finklestein D, Allen M et al (2007) A perivascular niche for brain tumor stem cells. Cancer Cell 11:69-82

10. Charles N, Ozawa T, Squatrito M, Bleau AM, Brennan CW, Hambardzumyan D, Holland EC (2010) Perivascular nitric oxide activates notch signaling and promotes stem-like character in PDGF-induced glioma cells. Cell Stem Cell 6:141-152. https://doi.org/10.1016/j.stem.2010.01.001

11. Chen J, Li GQ, Zhang L, Tang M, Cao X, Xu GL, Wu YZ (2018) Complement $\mathrm{C} 5 \mathrm{a} / \mathrm{C} 5 \mathrm{aR}$ pathway potentiates the pathogenesis of Gastric Cancer by down-regulating p21 expression. Cancer Lett 412:30-36. https://doi.org/10. 1016/j.canlet.2017.10.003

12. Cheng L, Huang Z, Zhou W, Wu Q, Donnola S, Liu JK, Fang X, Sloan AE, Mao Y, Lathia JD et al (2013) Glioblastoma Stem Cells generate vascular pericytes to support vessel function and tumor growth. Cell 153:139-152. https://doi.org/10.1016/j.cell.2013.02.021

13. Cho MS, Vasquez HG, Rupaimoole R, Pradeep S, Wu S, Zand B, Han HD, Rodriguez-Aguayo C, Bottsford-Miller J, Huang J et al (2014) Autocrine effects of tumor-derived complement. Cell Rep 6:1085-1095

14. Corrales L, Ajona D, Rafail S, Lasarte JJ, Riezu-Boj Jl, Lambris JD, Rouzaut A, Pajares MJ, Montuenga LM, Pio R (2012) Anaphylatoxin C5a creates a favorable microenvironment for lung cancer progression. J Immunol 189:4674-4683

15. Cortright DN, Meade R, Waters SM, Chenard BL, Krause JE (2009) C5a, but not C3a, increases VEGF secretion in ARPE-19 human retinal pigment epithelial cells. Curr Eye Res 34:57-61. https:/doi.org/10.1080/02713680802546658

16. Coulthard LG, Hawksworth OA, Li R, Balachandran A, Lee JD, Sepehrband F, Kurniawan N, Jeanes A, Simmons DG, Wolvetang E et al (2017) Complement C5aR1 Signaling Promotes Polarization and Proliferation of Embryonic Neural Progenitor Cells through PKCzeta. J Neurosci 37:5395-5407. https:// doi.org/10.1523/jneurosci.0525-17.2017

17. Cuddapah VA, Robel S, Watkins S, Sontheimer H (2014) A neurocentric perspective on glioma invasion. Nat Rev Neurosci 15:455-465. https://doi. org/10.1038/nrn3765

18. Daniele S, Costa B, Zappelli E, Da Pozzo E, Sestito S, Nesi G, Campiglia P, Marinelli L, Novellino E, Rapposelli S et al (2015) Combined inhibition of AKT/mTOR and MDM2 enhances glioblastoma Multiforme cell apoptosis and differentiation of cancer stem cells. Scientific reports 5:9956. https://doi. org/10.1038/srep09956

19. Davies DC (2002) Blood-brain barrier breakdown in septic encephalopathy and brain tumours. J Anat 200:639-646

20. Dejaegher J, Verschuere T, Vercalsteren E, Boon L, Cremer J, Sciot R, Van Gool SW, De Vleeschouwer S (2017) Characterization of PD-1 upregulation on tumor-infiltrating lymphocytes in human and murine gliomas and preclinical therapeutic blockade. Int J Cancer 141: 1891-1900 Doi https:// doi.org/10.1002/ijc.30877

21. Dimmeler S, Fleming I, Fisslthaler B, Hermann C, Busse R, Zeiher AM (1999) Activation of nitric oxide synthase in endothelial cells by Akt-dependent phosphorylation. Nature 399:601-605. https://doi.org/10.1038/21224

22. Du R, Lu KV, Petritsch C, Liu P, Ganss R, Passegue E, Song H, Vandenberg S, Johnson RS, Werb Z et al (2008) HIF1alpha induces the recruitment of bone marrow-derived vascular modulatory cells to regulate tumor angiogenesis and invasion. Cancer Cell 13:206-220. https://doi.org/10.1016/j.ccr.2008.01.034

23. Du Z, Jia D, Liu S, Wang F, Li G, Zhang Y, Cao X, Ling EA, Hao A (2009) Oct4 is expressed in human gliomas and promotes colony formation in glioma cells. Glia 57:724-733. https://doi.org/10.1002/glia.20800

24. Eder K, Kalman B (2015) The dynamics of interactions among immune and glioblastoma cells. NeuroMolecular Med 17:335-352. https://doi.org/10. 1007/s12017-015-8362-x

25. Fessler E, Borovski T, Medema JP (2015) Endothelial cells induce cancer stem cell features in differentiated glioblastoma cells via bFGF. Mol Cancer 14:157

26. Fraser DA, Bohlson SS, Jasinskiene N, Rawal N, Palmarini G, Ruiz S, Rochford $\mathrm{R}$, Tenner AJ (2006) C1q and MBL, components of the innate immune system, influence monocyte cytokine expression. J leukoc biol 80:107-116. https://doi.org/10.1189/jlb.1105683
27. Greijer AE, van der Groep P, Kemming D, Shvarts A, Semenza GL, Meijer GA, van de Wiel MA, Belien JA, van Diest PJ, van der Wall E (2005) Up-regulation of gene expression by hypoxia is mediated predominantly by hypoxia-inducible factor 1 (HIF-1). J Pathol 206:291-304. https://doi.org/10.1002/path.1778

28. Grivennikov SI, Greten FR, Karin M (2010) Immunity, inflammation, and cancer. Cell 140:883-899. https://doi.org/10.1016/j.cell.2010.01.025

29. Gu H, Mickler EA, Cummings OW, Sandusky GE, Weber DJ, Gracon A, Woodruff T, Wilkes DS, Vittal R (2014) Crosstalk between TGF-beta1 and complement activation augments epithelial injury in pulmonary fibrosis. FASEB J 28:4223-4234. https://doi.org/10.1096/fj.13-247650

30. Gunn L, Ding C, Liu M, Ma Y, Qi C, Cai Y, Hu X, Aggarwal D, Zhang HG, Yan $J$ (2012) Opposing roles for complement component C5a in tumor progression and the tumor microenvironment. J Immunol 189:2985-2994. https://doi.org/10.4049/jimmunol.1200846

31. Hambardzumyan D, Gutmann DH, Kettenmann H (2016) The role of microglia and macrophages in glioma maintenance and progression. Nat Neurosci 19:20-27. https://doi.org/10.1038/nn.4185

32. Hanahan D, Coussens LM (2012) Accessories to the crime: functions of cells recruited to the tumor microenvironment. Cancer Cell 21:309-322. https:// doi.org/10.1016/j.ccr.2012.02.022

33. Hanahan D, Weinberg RA (2011) Hallmarks of cancer: the next generation. Cell 144:646-674. https://doi.org/10.1016/j.cell.2011.02.013

34. Hanisch UK, Kettenmann H (2007) Microglia: active sensor and versatile effector cells in the normal and pathologic brain. Nat Neurosci 10:13871394. https://doi.org/10.1038/nn1997

35. Hawksworth OA, Coulthard LG, Taylor SM, Wolvetang EJ, Woodruff TM (2014) Brief report: complement C5a promotes human embryonic stem cell pluripotency in the absence of FGF2. Stem cells 32:3278-3284. https://doi. org/10.1002/stem.1801

36. Haynes T, Luz-Madrigal A, Reis ES, Echeverri Ruiz NP, Grajales-Esquivel E, Tzekou A, Tsonis PA, Lambris JD, Del Rio-Tsonis K (2013) Complement anaphylatoxin $\mathrm{C} 3 \mathrm{a}$ is a potent inducer of embryonic chick retina regeneration. Nat Commun 4: 2312 Doi https://doi.org/10.1038/ncomms3312

37. Hernandez C, Huebener P, Schwabe RF (2016) Damage-associated molecular patterns in cancer: a double-edged sword. Oncogene 35:59315941. https://doi.org/10.1038/onc.2016.104

38. Honczarenko M, Ratajczak MZ, Nicholson-Weller A, Silberstein LE (2005) Complement C3a enhances CXCL12 (SDF-1)-mediated chemotaxis of bone marrow hematopoietic cells independently of C3a receptor. J Immunol 175:3698-3706

39. Infanger DW, Cho Y, Lopez BS, Mohanan S, Liu SC, Gursel D, Boockvar JA, Fischbach C (2013) Glioblastoma stem cells are regulated by interleukin-8 signaling in a tumoral perivascular niche. Cancer Res 73:7079-7089

40. Jacob A, Alexander JJ (2014) Complement and blood-brain barrier integrity. Mol Immunol 61:149-152. https://doi.org/10.1016/j.molimm.2014.06.039

41. Kahlert UD, Maciaczyk D, Doostkam S, Orr BA, Simons B, Bogiel T, Reithmeier T, Prinz M, Schubert J, Niedermann G et al (2012) Activation of canonical WNT/beta-catenin signaling enhances in vitro motility of glioblastoma cells by activation of ZEB1 and other activators of epithelial-to-mesenchymal transition. Cancer Lett 325:42-53. https://doi. org/10.1016/j.canlet.2012.05.024

42. Kalani MY, Cheshier SH, Cord BJ, Bababeygy SR, Vogel H, Weissman IL, Palmer TD, Nusse R (2008) Wnt-mediated self-renewal of neural stem/ progenitor cells. Proc Natl Acad Sci U S A 105:16970-16975. https://doi.org/ 10.1073/pnas.0808616105

43. Kaplan AP, Ghebrehiwet B (2010) The plasma bradykinin-forming pathways and its interrelationships with complement. Mol Immunol 47:2161-2169. https://doi.org/10.1016/j.molimm.2010.05.010

44. Keir LS, Firth R, Aponik L, Feitelberg D, Sakimoto S, Aguilar E, Welsh Gl, Richards A, Usui Y, Satchell SC et al (2017) VEGF regulates local inhibitory complement proteins in the eye and kidney. J Clin Invest 127:199-214. https://doi.org/10.1172/jci86418

45. Kemper C, Chan AC, Green JM, Brett KA, Murphy KM, Atkinson JP (2003) Activation of human CD4+ cells with CD3 and CD46 induces a T-regulatory cell 1 phenotype. Nature 421:388-392. https://doi.org/10.1038/nature01315

46. Lathia JD, Heddleston JM, Venere M, Rich JN (2011) Deadly teamwork: neural cancer stem cells and the tumor microenvironment. Cell Stem Cell 8: 482-485. https://doi.org/10.1016/j.stem.2011.04.013

47. Le Buanec H, Gougeon ML, Mathian A, Lebon P, Dupont JM, Peltre G, Hemon P, Schmid M, Bizzini B, Kunding T et al (2011) IFN-alpha and CD46 stimulation are associated with active lupus and skew natural T regulatory 
cell differentiation to type 1 regulatory T (Tr1) Cell. Proc Natl Acad Sci U S A 108:18995-19000. https://doi.org/10.1073/pnas.1113301108

48. Le Friec G, Sheppard D, Whiteman P, Karsten CM, Shamoun SA, Laing A, Bugeon L, Dallman MJ, Melchionna T, Chillakuri C et al (2012) The CD46-Jagged1 interaction is critical for human TH1 immunity. Nat Immunol 13:1213-1221

49. Li Z, Bao S, Wu Q, Wang H, Eyler C, Sathornsumetee S, Shi Q, Cao Y, Lathia J, RE ML et al (2009) Hypoxia-inducible factors regulate tumorigenic capacity of glioma stem cells. Cancer Cell 15:501-513. https://doi.org/10. 1016/j.ccr.2009.03.018

50. Liszewski MK, Kolev M, Le Friec G, Leung M, Bertram PG, Fara AF, Subias M, Pickering MC, Drouet C, Meri S et al (2013) Intracellular complement activation sustains $\mathrm{T}$ cell homeostasis and mediates effector Differentiation. Immunity 39:1143-1157. https://doi.org/10.1016/j.immuni.2013.10.018

51. Mamidi S, Hone S, Kirschfink M (2017) The complement system in cancer: ambivalence between tumour destruction and promotion. Immunobiology 222:45-54. https://doi.org/10.1016/j.imbio.2015.11.008

52. Mantovani A, Allavena P, Sica A, Balkwill F (2008) Cancer-related inflammation. Nature 454:436-444. https://doi.org/10.1038/nature07205

53. Markiewski MM, DeAngelis RA, Benencia F, Ricklin-Lichtsteiner SK, Koutoulaki A, Gerard C, Coukos G, Lambris JD (2008) Modulation of the antitumor immune response by complement. Nat Immunol 9:1225-1235. https://doi. org/10.1038/ni.1655

54. Mastellos DC (2014) Complement emerges as a masterful regulator of CNS homeostasis, neural synaptic plasticity and cognitive function. Exp Neurol 261:469-474. https://doi.org/10.1016/j.expneurol.2014.06.019

55. McGeer PL, Lee M, McGeer EG (2017) A review of human diseases caused or exacerbated by aberrant complement activation. Neurobiol Aging 52:12-22. https://doi.org/10.1016/.j.neurobiolaging.2016.12.017

56. Merle NS, Church SE, Fremeaux-Bacchi V, Roumenina LT (2015) Complement system part I - molecular mechanisms of activation and regulation. Front Immunol 6:262. https://doi.org/10.3389/fimmu.2015.00262

57. Montalto MC, Hart ML, Jordan JE, Wada K, Stahl GL (2003) Role for complement in mediating intestinal nitric oxide synthase-2 and superoxide dismutase expression. Am J Physiol Gastrointest Liver Physiol 285:G197G206. https://doi.org/10.1152/ajpgi.00029.2003

58. Montana V, Sontheimer H (2011) Bradykinin promotes the chemotactic invasion of primary brain tumors. J Neurosci 31:4858-4867. https://doi.org/ 10.1523/jneurosci.3825-10.2011

59. Morgan BP, Boyd C, Bubeck D (2017) Molecular cell biology of complement membrane attack. Seminars in cell \& developmental biology: Doi. https:// doi.org/10.1016/j.semcdb.2017.06.009

60. Morgan BP, Gasque P (1996) Expression of complement in the brain: role in health and disease. Immunol Today 17:461-466

61. Naito AT, Sumida T, Nomura S, Liu ML, Higo T, Nakagawa A, Okada K, Sakai T, Hashimoto A, Hara Y et al (2012) Complement C1q activates canonical Wnt signaling and promotes aging-related phenotypes. Cell 149:1298-1313

62. Nitta H, Murakami Y, Wada Y, Eto M, Baba H, Imamura T (2014) Cancer cells release anaphylatoxin $\mathrm{C} 5 \mathrm{a}$ from $\mathrm{C} 5$ by serine protease to enhance invasiveness. Oncol Rep 32:1715-1719. https://doi.org/10.3892/or.2014.3341

63. Nunez-Cruz S, Gimotty PA, Guerra MW, Connolly DC, Wu YQ, DeAngelis RA, Lambris JD, Coukos G, Scholler N (2012) Genetic and pharmacologic inhibition of complement impairs endothelial cell function and ablates ovarian cancer neovascularization. Neoplasia 14:994-1004

64. O'Garra A, Barrat FJ, Castro AG, Vicari A, Hawrylowicz C (2008) Strategies for use of IL-10 or its antagonists in human disease. Immunol Rev 223:114-131. https://doi.org/10.1111/j.1600-065X.2008.00635.x

65. Ooi YC, Tran P, Ung N, Thill K, Trang A, Fong BM, Nagasawa DT, Lim M, Yang I (2014) The role of regulatory T-cells in glioma immunology. Clin Neurol Neurosurg 119:125-132. https://doi.org/10.1016/..clineuro.2013.12.004

66. Pedersen ED, Froyland E, Kvissel AK, Pharo AM, Skalhegg BS, Rootwelt T, Mollnes TE (2007) Expression of complement regulators and receptors on human NT2-N neurons--effect of hypoxia and reoxygenation. Mol Immunol 44:2459-2468. https://doi.org/10.1016/j.molimm.2006.10.022

67. Peerschke El, Ghebrehiwet B (2014) CC19R/CR and gC1aR/p33: observations in cancer. Mol Immunol 61:100-109

68. Perianayagam MC, Balakrishnan VS, King AJ, Pereira BJ, Jaber BL (2002) C5a delays apoptosis of human neutrophils by a phosphatidylinositol 3kinase-signaling pathway. Kidney Int 61:456-463. https://doi.org/10.1046/ j.1523-1755.2002.00139.x

69. Qiang L, Wu T, Zhang HW, Lu N, Hu R, Wang YJ, Zhao L, Chen FH, Wang XT, You QD et al (2012) HIF-1alpha is critical for hypoxia-mediated maintenance of glioblastoma Stem Cells by activating Notch signaling pathway. Cell Death Differ 19:284-294. https://doi.org/10.1038/cdd.2011.95

70. Qiu Y, Marquez-Curtis LA, Janowska-Wieczorek A (2012) Mesenchymal stromal cells derived from umbilical cord blood migrate in response to complement C1q. Cytotherapy 14:285-295

71. Rampazzo E, Persano L, Pistollato F, Moro E, Frasson C, Porazzi P, Della Puppa A, Bresolin S, Battilana G, Indraccolo S et al (2013) Wnt activation promotes neuronal differentiation of glioblastoma. Cell Death Dis 4:e500. https://doi.org/10.1038/cddis.2013.32

72. Rao S, Sengupta R, Choe EJ, Woerner BM, Jackson E, Sun T, Leonard J, Piwnica-Worms D, Rubin JB (2012) CXCL12 mediates trophic interactions between endothelial and tumor cells in glioblastoma. PLoS One 7:e33005

73. Raychaudhuri B, Rayman P, Ireland J, Ko J, Rini B, Borden EC, Garcia J, Vogelbaum MA, Finke J (2011) Myeloid-derived suppressor cell accumulation and function in patients with newly diagnosed glioblastoma. Neuro-Oncology 13:591-599

74. Reis ES, Mastellos DC, Ricklin D, Mantovani A, Lambris JD (2017) Complement in cancer: untangling an intricate relationship. Nature reviews Immunology: Doi. https://doi.org/10.1038/nri.2017.97

75. Ricklin D, Hajishengallis G, Yang K, Lambris JD (2010) Complement: a key system for immune surveillance and homeostasis. Nat Immunol 11:785-797. https://doi.org/10.1038/ni.1923

76. Sakiyama H, Kaji K, Nakagawa K, Nagino K (1998) Inhibition of bFGF activity by complement C1s: covalent binding of C1s with bFGF. Cell Biochem Funct 16:159-163

77. Sarma JV, Ward PA (2012) New developments in C5a receptor signaling. Cell health and cytoskeleton 4:73-82. https://doi.org/10.2147/chc.s27233

78. Sayour EJ, McLendon P, McLendon R, De Leon G, Reynolds R, Kresak J, Sampson JH, Mitchell DA (2015) Increased proportion of FoxP3+ regulatory $T$ cells in tumor infiltrating lymphocytes is associated with tumor recurrence and reduced survival in patients with glioblastoma. Cancer immunology, immunotherapy: Cll 64:419-427. https://doi.org/10.1007/s00262-014-1651-7

79. Schraufstatter IU, Discipio RG, Zhao M, Khaldoyanidi SK (2009) C3a and C5a are chemotactic factors for human mesenchymal stem cells, which cause prolonged ERK1/2 phosphorylation. Journal of immunology (Baltimore, Md : 1950) 182: 3827-3836

80. Sharma A, Shiras A (2016) Cancer stem cell-vascular endothelial cell interactions in glioblastoma. Biochem Biophys Res Commun 473:688-692. https://doi.org/10.1016/j.bbrc.2015.12.022

81. Shen $Q$, Goderie SK, Jin L, Karanth N, Sun Y, Abramova N, Vincent $P$, Pumiglia K, Temple S (2004) Endothelial cells stimulate self-renewal and expand neurogenesis of neural stem cells. Science 304:1338-1340

82. Sherry MM, Reeves A, Wu JK, Cochran BH (2009) STAT3 is required for proliferation and maintenance of multipotency in glioblastoma Stem Cells. Stem cells (Dayton, Ohio) 27:2383-2392. https://doi.org/10.1002/stem.185

83. Shinjyo N, Stahlberg A, Dragunow M, Pekny M, Pekna M (2009) Complement-derived anaphylatoxin C3a regulates in vitro differentiation and migration of neural progenitor cells. Stem cells (Dayton, Ohio) 27:2824-2832

84. Simone S, Rascio F, Castellano G, Divella C, Chieti A, Ditonno P, Battaglia M, Crovace A, Staffieri F, Oortwijn B et al (2014) Complement-dependent NADPH oxidase enzyme activation in renal ischemia/reperfusion injury. Free Radic Biol Med 74:263-273

85. Singh SK, Hawkins C, Clarke ID, Squire JA, Bayani J, Hide T, Henkelman RM, Cusimano MD, Dirks PB (2004) Identification of human brain tumour initiating cells. Nature 432:396-401. https://doi.org/10.1038/nature03128

86. Speidl WS, Kastl SP, Hutter R, Katsaros KM, Kaun C, Bauriedel G, Maurer G, Huber K, Badimon JJ, Wojta J (2011) The complement component C5a is present in human coronary lesions in vivo and induces the expression of MMP-1 and MMP-9 in human macrophages in vitro. FASEB j 25:35-44

87. Strainic MG, Liu J, Huang D, An F, Lalli PN, Muqim N, Shapiro VS, Dubyak GR, Heeger PS, Medof ME (2008) Locally produced complement fragments C5a and C3a provide both costimulatory and survival signals to naive CD4+ T cells. Immunity 28:425-435. https://doi.org/10.1016/j.immuni.2008.02.001

88. Suva ML, Rheinbay E, Gillespie SM, Patel AP, Wakimoto H, Rabkin SD, Riggi N, Chi AS, Cahill DP, Nahed BV et al (2014) Reconstructing and reprogramming the tumor-propagating potential of glioblastoma stem-like Cell. Cell 157:580-594. https://doi.org/10.1016/..cell.2014.02.030

89. Taylor RP, Lindorfer MA (2016) Cytotoxic mechanisms of immunotherapy: harnessing complement in the action of anti-tumor monoclonal antibodies. Semin Immunol 28:309-316. https://doi.org/10.1016/j.smim.2016.03.003 
90. Thomas TM, Yu JS (2017) Metabolic regulation of glioma stem-like cells in the tumor micro-environment. Cancer Lett 408:174-181. https://doi. org/10.1016/j.canlet.2017.07.014

91. Thurman JM, Renner B, Kunchithapautham K, Ferreira VP, Pangburn MK, Ablonczy Z, Tomlinson S, Holers VM, Rohrer B (2009) Oxidative stress renders retinal pigment epithelial cells susceptible to complement-mediated injury. J Biol Chem 284:16939-16947. https:// doi.org/10.1074/jbc.M808166200

92. van den Berg RH, Faber-Krol MC, Sim RB, Daha MR (1998) The first subcomponent of complement, C1q, triggers the production of IL-8, IL-6, and monocyte chemoattractant peptide-1 by human umbilical vein endothelial Cell. J Immunol 161:6924-6930

93. Veerhuis R, Nielsen HM, Tenner AJ (2011) Complement in the brain. Mol Immunol 48:1592-1603. https://doi.org/10.1016/j.molimm.2011.04.003

94. Vesely MD, Kershaw MH, Schreiber RD, Smyth MJ (2011) Natural innate and adaptive immunity to cancer. Annu Rev Immunol 29:235-271. https://doi. org/10.1146/annurev-immunol-031210-101324

95. Wainwright DA, Sengupta S, Han Y, Lesniak MS (2011) Thymus-derived rather than tumor-induced regulatory $\mathrm{T}$ cells predominate in brain tumors. Neuro-Oncology 13:1308-1323. https://doi.org/10.1093/neuonc/nor134

96. Walport MJ (2001) Complement. First of two parts. N Engl J Med 344:10581066. https://doi.org/10.1056/nejm200104053441406

97. Wang L, Han G, Wang R, Chen G, Xu R, Xiao H, Li X, Geng S, Li Y, Li X et al (2010) Regulation of IL-8 production by complement-activated product, C5a, in vitro and in vivo during sepsis. Clin Immunol 137:157-165

98. Wurdinger T, Deumelandt K, van der Vliet HJ, Wesseling P, de Gruijl TD (2014) Mechanisms of intimate and long-distance cross-talk between glioma and myeloid cells: how to break a vicious cycle. Biochim Biophys Acta 1846: 560-575 Doi https://doi.org/10.1016/j.bbcan.2014.10.003

99. Yan K, Wu Q, Yan DH, Lee CH, Rahim N, Tritschler I, DeVecchio J, Kalady MF, Hjelmeland AB, Rich JN (2014) Glioma cancer stem cells secrete Gremlin1 to promote their maintenance within the tumor hierarchy. Genes Dev 28: 1085-1100. https://doi.org/10.1101/gad.235515.113

100. Yanai R, Thanos A, Connor KM (2012) Complement involvement in neovascular ocular diseases. Adv Exp Med Biol 946:161-183. https://doi.org/ 10.1007/978-1-4614-0106-3_10

101. Yang C, Yang L, Liu Y (2014) Soluble complement complex C5b-9 promotes microglia activation. J Neuroimmunol 267:16-19. https://doi. org/10.1016/j.jneuroim.2013.11.007

102. Yang YH, Tsai IJ, Chang CJ, Chuang YH, Hsu HY, Chiang BL (2015) The interaction between circulating complement proteins and cutaneous microvascular endothelial cells in the development of childhood HenochSchonlein purpura. PLoS One 10:e0120411

103. Yu MO, Park KJ, Park DH, Chung YG, Chi SG, Kang SH (2015) Reactive oxygen species production has a critical role in hypoxia-induced Stat3 activation and angiogenesis in human glioblastoma. J Neuro-Oncol

104. Zajc I, Hreljac I, Lah T (2006) Cathepsin L affects apoptosis of glioblastoma cells: a potential implication in the design of cancer therapeutics. Anticancer Res 26:3357-3364

105. Zhang YE (2009) Non-Smad pathways in TGF-beta signaling. Cell Res 19: 128-139. https://doi.org/10.1038/cr.2008.328

Ready to submit your research? Choose BMC and benefit from:

- fast, convenient online submission

- thorough peer review by experienced researchers in your field

- rapid publication on acceptance

- support for research data, including large and complex data types

- gold Open Access which fosters wider collaboration and increased citations

- maximum visibility for your research: over $100 \mathrm{M}$ website views per year

At BMC, research is always in progress.

Learn more biomedcentral.com/submissions 